\title{
Viabilidade financeira da inseminação artificial em tempo fixo de bezerros cruzados Nelore e Aberdeen Angus
}

Economic feasibility of timed artificial insemination of Nellore and Aberdeen Angus crossbred calves

\section{Nelson Zuchi Neto ${ }^{1}$; Flávio Carlos Dalchiavon²*}

${ }^{1}$ Engenheiro Ambiental - Rua Zelino Agostinho Lorenzetti, Caixa Postal 84 - Centro - CEP 78307-000 - Campos de Júlio (MT), Brasil

2* Engenheiro Agrônomo, Doutor em Agronomia, Instituto Federal de Mato Grosso, Campus Campo Novo do Parecis, Rodovia MT 235, km 12, s/n, Caixa Postal n 100, Zona Rural - CEP 7360-000 - Campo Novo do Parecis (MT), Brasil <flavio.dalchiavon@cnp.ifmt.edu.br>

\section{Resumo}

O cruzamento entre taurinos e zebuínos através de Inseminação Artificial em Tempo Fixo [IATF] é uma realidade presente em várias propriedades rurais no Brasil. Visando as vantagens da IATF em conjunto com as vantagens do cruzamento industrial o objetivo foi verificar a viabilidade financeira desta atividade em uma propriedade no município de Nova Lacerda, MT. Para tal, utilizou-se as ferramentas de matemática financeira Valor Presente Líquido [VPL], Taxa Interna de Retorno [TIR] e Payback. O projeto se mostrou viável com um VPL acima de R\$300 mil, TIR de 23,03\% e Payback descontado de aproximadamente oito anos. A venda de descartes e a suplementação dos bezerros em sistema de "creep feeding" se mostraram importantes para a viabilidade deste projeto.

Palavras-chave: cerrado mato-grossense, cruzamento industrial, pecuária de corte

\begin{abstract}
Bos taurus and Bos indicus crossbred through Timed Artificial Insemination [TAП] is present in several farms in Brazil. Aiming the advantages of the TAI together with industrial crossing, the objective was to verify the economic feasibility of this activity on a farm in the city of Nova Lacerda, MT. Financial mathematics tools like Net Present Value [NPV], Internal Rate of Return [IRR] and Payback were used. The project was feasible with a NPV above R $\$ 300$ thousand, an IRR of $23.03 \%$ and a Discounted Payback of approximately eight years. The sale of discards matrix and the supplementation of calves in a creep feeding system showed to be important for the viability of this project.
\end{abstract}

Keywords: Brazilian savannah, crossbreeding, beef cattle

\section{Introdução}

Uma técnica que transforma a carne em um produto de alta qualidade para exportação vem sendo implantada na cadeia produtiva da carne bovina brasileira. $O$ cruzamento entre taurinos e zebuínos através de inseminação artificial é uma realidade presente em várias propriedades rurais no Brasil e especialmente no Estado de Mato Grosso (Artmann, 2014). A inseminação artificial em tempo fixo é um mecanismo que permite a sincronização do estro e da ovulação sem a necessidade de observação do cio, além de concentrar as inseminações e os nascimentos em épocas programadas, reduzindo o intervalo entre partos e favorecendo ao produtor uma otimização no manejo da propriedade (Furtado et al., 2011).

Há inúmeras vantagens na utilização da inseminação artificial, como a padronização do rebanho, a organização do trabalho na fazenda e principalmente o processo de melhoramento genético e a obtenção de animais com maior potencial de produção e reprodução (Baruselli et al., 2015). Ainda assim, no Brasil, apenas uma minoria dos proprietários utiliza a inseminação artificial (Furtado et al., 2011).
Os sistemas de produção da bovinocultura de corte são constituídos, em sua maioria, pelas fases de cria, recria e terminação, de forma que suas características da pré-desmama são de grande importância econômica nesta atividade (Pereira e Muniz, 2013).

Desempenho superior do grupo F1 (bezerros oriundos do cruzamento industrial entre Nelore e Aberdeen Angus) em relação aos da raça Nelore foi verificado por Dias et al. (2015), com diferença significativa no peso ao nascer, peso ajustado aos 205 dias, peso ao desmame e ganho de peso diário entre o nascimento e os 205 dias, demonstrando mais vantagens na utilização de tecnologias que permitem o cruzamento industrial.

Neste mesmo sentido, e visando às vantagens da inseminação artificial em conjunto com as vantagens do cruzamento industrial entre Bos indicus e Bos taurus, foi implantada, em uma fazenda no município de Nova Lacerda, MT, um aperfeiçoamento na técnica da inseminação artificial, a Inseminação Artificial em Tempo Fixo [IATF], tecnologia que permite ao produtor escolher o momento de inseminar as matrizes sem a necessidade de esperar que a natureza o determine, 
evitando, assim, o processo de visualização de cio (Inforzato et al., 2008).

Assim, objetivou-se demonstrar a viabilidade financeira da inseminação artificial em tempo fixo e do processo de cria dos bezerros $1 / 2$ sangue Aberdeen Angus e $1 / 2$ sangue Nelores.

\section{Material e Métodos}

A viabilidade financeira da Inseminação Artificial em Tempo Fixo [IATF] foi analisada em uma propriedade no município de Nova Lacerda, Mato Grosso, na região do Vale do Guaporé, durante o ano de 2015. Utilizou-se uma população de 1.000 bovinos criados em regime de pastejo, sendo as matrizes da raça Nelore e o sêmen de touros Aberdeen Angus, e os bezerros, provenientes de tal inseminação, até a idade de desmama.

Foi considerado como valor de compra das mil novilhas de 18 meses a quantia de $\mathrm{R} \$ 1.100,00$ cada, resultando num investimento inicial (ano zero) de $\mathrm{R} \$$ 1.100.000,00.

As matrizes utilizadas foram mantidas em sistema de pecuária extensiva em pasto de Brachiaria decumbens com suplementação a base de sal mineral. Os bezerros em amamentação foram criados em sistema de "creepfeeding", com pastejo e suplemento mineral proteico energético.

"Creep feeding" é um método de suplementação para bezerros onde o local de alimentação é feito de uma forma que apenas os bezerros tenham acesso, não permitindo o acesso das matrizes. Segundo Dantas et al. (2010), "creep-feeding" é a prática de administrar aos bezerros alimento suplementar antes do desmame, aumentando o ganho de peso durante o período de amamentação e obtendo-se animais mais pesados ao desmame.

Como endectocida foi utilizada Ivermectina (4\%) com liberação programada. Para combate da mosca do chifre foi utilizado brinco mosquicida a base de diazinon. Todas as matrizes foram identificadas numericamente com brincos de identificação.

No processo de indução de estro e inseminação artificial foram utilizados os seguintes materiais que compõem os protocolos (exceto o sêmen): Implante intravaginal de liberação lenta de progesterona; Estrógeno injetável; Agente hormonal liberador de LH à base de Cipionato de Estradiol injetável; Agente Luteolítico e Sincronizador de cio (Cloprostenol Sódico) injetável; Gonadotrofina Coriônica Equina injetável, e; Sêmen bovino da raça Aberdeen Angus.

O protocolo da IATF utilizado foi realizado em quatro etapas: no dia zero (D0) foram aplicados os implantes intravaginais e injetado o estrógeno; no dia 8 (D8) foram retirados os implantes de progesterona e injetado o Cipionato de Estradiol, Cloprostenol Sódico e a Gonadotrofina Coriônica Equina; no dia 10 (D10) foi realizada a inseminação artificial e 35 dias após a IATF foi realizado o diagnóstico de gestação por ultrassonografia. O protocolo foi repetido, por uma vez, nas matrizes com diagnóstico de gestação negativo.

Para a análise dos dados, foram utilizadas ferramentas de matemática financeira para avaliar a viabilidade do projeto a partir de um fluxo de caixa avaliando os indicadores Valor Presente Líquido [VPL], Taxa Interna de Retorno [TIR] e Payback. Imposto de renda não foi considerado neste estudo.

A Taxa Mínima de Atratividade [TMA] considerada foi de $15 \%$. Todos os preços apresentados neste projeto são preços reais (ano base 2015), obtidos por orçamentos feitos pelo proprietário da fazenda no comércio regional.

\section{Resultados e Discussão}

Com as 1000 novilhas inseminadas, após 35 dias da IATF, foram diagnosticadas 509 novilhas prenhes, ou seja, $50,90 \%$ de aproveitamento. No momento do diagnóstico de gestação, as novilhas que apresentaram resultado negativo, passaram pelo protocolo de IATF novamente. Passados 35 dias da segunda IATF, foi passado o ultrassom novamente e constatado que 244 novilhas estavam prenhes, ou seja, 49,69\% delas apresentaram resultado positivo, totalizando, assim, 735 $(73,5 \%)$ novilhas prenhes após duas IATF.

Os protocolos de sincronização para IATF objetivam induzir a emergência de uma nova onda de crescimento folicular, controlar a duração do crescimento folicular até o estágio pré-ovulatório, sincronizar a inserção e a retirada da fonte de progesterona exógena (implante auricular ou dispositivo intravaginal) e endógena (prostaglandina F2) e induzir a ovulação sincronizada em todos os animais simultaneamente (Baruselli et al., 2015).

Os bezerros em amamentação foram criados em sistema de "creep-feeding", com suplemento mineral proteico energético a partir dos 60 dias de idade, além do pastejo.

Os animais adultos (matrizes) consumiram cerca de $80 \mathrm{~g} \mathrm{dia}^{-1}$ de sal mineral, o que resulta em uma média de um saco de $30 \mathrm{~kg} \mathrm{ano}^{-1}$. animal ${ }^{-1}$. Os bezerros em sistema de "creep-feeding" consumiram, em média, $800 \mathrm{~g} \mathrm{dia}^{-1}$ de suplemento mineral proteico, resultando num consumo de quatro sacos de $30 \mathrm{~kg}$ durante os cinco meses de suplementação (a partir dos 60 dias de vida até o final do sétimo mês de idade, momento em que foram desmamados e vendidos). O desempenho do período pré-desmama é importante por se tratar do primeiro resultado de produtividade animal, uma vez que ao final do ciclo do animal, a classificação e tipificação das carcaças possibilitam enquadrá-las em diferentes classes e, assim, direcioná-las a diferentes mercados (Dias et al., 2015).

Para a sanidade dos animais foram aplicadas vacinas para Brucelose (bezerras fêmeas), Carbúnculo em todos os bezerros, com reforço após 30 dias da primeira vacinação, e também para a febre aftosa, sendo que na etapa de vacinação do mês de maio foram vacinados os 
animais de até 24 meses de idade e na etapa do mês de novembro, todos os animais do rebanho foram vacinados. Todas as matrizes receberam brincos mosquicidas duas vezes ao ano. Todo o rebanho recebeu também duas doses anuais de endectocida.

Considerando que o valor do $\mathrm{kg}$ dos bezerros machos vendidos para recria foi de $\mathrm{R} \$ 6,50$ e o das fêmeas de $\mathrm{R} \$ 5,50$ e que a média de peso dos bezerros vendidos foi de $208 \mathrm{~kg}$, em média, o total por bezerro foi de $\mathrm{R} \$ 1.248,00$. Por ser um ano com pouca pluviosidade na propriedade, ocorreu baixa disponibilidade de forragem, consequentemente, o peso médio dos bezerros foi inferior ao esperado e praticado em anos anteriores. Porém, a suplementação proteica dos bezerros "creep-feeding" se mostrou importante para minimizar os efeitos negativos da baixa disponibilidade de forragem.

Em relação ao custo da terra e pastagem foi considerado o valor corrente por vaca do arrendamento de pastagem por mês na região da fazenda estudada de $\mathrm{R} \$ 25,00$.

As despesas com protocolo de inseminação, sêmen, inseminador e dez visitas anuais (duas para cada um dos cinco lotes em que o rebanho total foi dividido) de um veterinário à propriedade somaram um montante de $\mathrm{R} \$$ 68.400,41 conforme demonstrado na tabela 1 .

Tabela 1. Custos anuais da inseminação dos cinco lotes de animais da fazenda em estudo

\begin{tabular}{lccc}
\hline \multicolumn{1}{c}{ Produto } & Unidades & Valor Unitário & Valor Total \\
\hline & & -1491 & 15,50 \\
Sêmen & 1491 & 15,01 & $23.110,50$ \\
Protocolos & 1491 & 10,00 & $22.379,91$ \\
Inseminações & 10 & 800,00 & $14.910,00$ \\
Visitas do veterinário & - & - & $8.000,00$ \\
\hline Subtotal & & & $68.400,41$ \\
\hline
\end{tabular}

Fonte: Resultados originais da pesquisa

Para a sanidade animal, obteve-se custo de $\mathrm{R} \$$ 15.499,66, relacionado às vacinas contra febre aftosa, brucelose e carbúnculo, além do endectocida e dos brincos mosquicidas (Tabela 2).

Os gastos com alimentação somaram R $\$ 154.226,04$, sendo o sal mineral, disponibilizado para os animais adultos, e o suplemento mineral proteico, para os bezerros por meio do "creep-feeding" (Tabela 3).

As despesas com colaboradores, reposição de matrizes e brincos de identificação e arrendamento de pasto somaram R $\$ 665.580,00$ (Tabela 4).

Tabela 2. Custos anuais relacionados à sanidade animal da fazenda em estudo

\begin{tabular}{|c|c|c|c|}
\hline Produto & Unidades & Valor Unitário & Valor Total \\
\hline & & \multicolumn{2}{|c|}{ 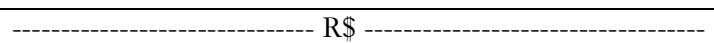 } \\
\hline Vacina Aftosa & 2146 & 1,24 & $2.661,04$ \\
\hline Vacina Carbúnculo & 1146 & 1,18 & $1.352,28$ \\
\hline Vacina Brucelose & 279 & 2,46 & 686,34 \\
\hline Endectocida (L) & 18 & 300,00 & $5.400,00$ \\
\hline Brinco Mosquicida & 2.000 & 2,70 & $5.400,00$ \\
\hline Subtotal & - & - & $15.499,66$ \\
\hline
\end{tabular}

Fonte: Resultados originais da pesquisa

Os custos com colaboradores apresentados (Tabela 4) refere-se à remuneração de um vaqueiro, com salário mensal de $\mathrm{R} \$ 2.500,00$, e dois ajudantes, com salário mensal de R \$ 1.500,00 cada. Na soma do montante estão inclusos férias, décimo terceiro salário e demais encargos.

Com base nas tabelas 3 e 4, percebeu-se, ainda, que mão de obra, alimentação e matéria prima (matrizes e terra) foram os maiores montantes de despesas deste estudo. $\mathrm{O}$ item reposição de matrizes refereu-se à reposição das matrizes que tiveram diagnóstico de gestação negativo, mesmo após as duas IATFs, sendo estas vendidas para o abate.
Tabela 3. Custos anuais de alimentação dos animais da fazenda em estudo

\begin{tabular}{|c|c|c|c|}
\hline Produto & Unidades & $\begin{array}{c}\text { Valor } \\
\text { Unitário }\end{array}$ & Valor Total \\
\hline & & \multicolumn{2}{|c|}{ - R\$ - - } \\
\hline $\begin{array}{l}\text { Sal Mineral } \\
\text { Suplemento }\end{array}$ & 1.000 & 58,26 & $58.260,00$ \\
\hline $\begin{array}{l}\text { Mineral } \\
\text { Proteico }\end{array}$ & 2292 & 41,87 & $95.966,04$ \\
\hline Subtotal & - & - & $154.226,04$ \\
\hline
\end{tabular}


Tabela 4. Outros custos anuais da fazenda em estudo

\begin{tabular}{lccc}
\hline Produto & Unidade & $\begin{array}{c}\text { Valor } \\
\text { Unitário }\end{array}$ & Valor Total \\
\hline $\begin{array}{l}\text { Colaboradores } \\
\begin{array}{l}\text { Brinco } \\
\text { identificação }\end{array}\end{array}$ & 3 & --------- R $\$----------$ \\
$\begin{array}{l}\text { Reposição } \\
\text { matrizes }\end{array}$ & 1.000 & 2,58 & $2.580,00$ \\
$\begin{array}{l}\text { Arrendamento } \\
\text { anual }\end{array}$ & $\begin{array}{c}\text { 1.000/ } \\
\text { mês }\end{array}$ & 25,00 & $300.000,00$ \\
\hline Subtotal & - & - & $665.580,00$ \\
\hline
\end{tabular}

Fonte: Resultados originais da pesquisa

Observa-se na tabela 5 que a soma das despesas no ano 1 foi menor que as despesas nos demais anos devido à reposição de matrizes, que não foram necessárias neste período, ocorrendo diminuição das despesas de $\mathrm{R} \$$

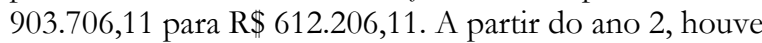
descartes de matrizes com diagnóstico de prenhes negativo, sendo necessária a reposição destas, aumentando assim as despesas. Da mesma forma, as receitas referentes ao ano 10 foram inferiores às demais receitas, pois neste ano não foram vendidas matrizes descartes e sim vendidas todas as matrizes, entrando a receita como valor residual (Tabela 5).

Assim, aplicando o conceito de Valor Presente Líquido [VPL] ao fluxo de caixa demonstrado na Tabela 5, com Taxa Mínima de Atratividade [TMA] de 15\%, observou-se VPL de R \$ 378.667,74, demonstrando a viabilidade do projeto, confirmada pelo resultado de 23,03\% da Taxa Interna de Retorno [TIR] em um período de dez anos.

Os elevados valores de VPL e TIR (Tabela 5) devemse, principalmente, ao Valor Residual, que foi maior que o investimento inicial e receitas anuais, aumentando significativamente os resultados do fluxo de caixa.

Foi verificado índice de óbito de $0,9 \%$ de matrizes ao ano. Ao final do período de dez anos do fluxo de caixa (Tabela 5), como valor residual, foi considerada a venda das matrizes como matrizes gordas, com 13 arrobas por cabeça e um valor de $\mathrm{R} \$ 120,00$ por arroba. Assim, no valor residual foram descontadas as 90 matrizes falecidas neste período de 10 anos.

Tabela 5. Fluxo de caixa da inseminação artificial em tempo fixo e do processo de cria dos bezerros $1 / 2$ sangue Aberdeen Angus e $1 / 2$ sangue Nelores

\begin{tabular}{|c|c|c|c|c|c|c|c|}
\hline Ano & Investimento & Despesas & Receitas & Valor Residual & FC Projeto & VPL & TIR \\
\hline & --------------------- & & & $R \$$ & ------------------- & ------------- & $--\%$ \\
\hline 0 & $1.100 .000,00$ & & & & $1.100 .000,00$ & $378.667,74$ & 23,03 \\
\hline 1 & & $612.206,11$ & $1.096 .704,00$ & & $484.497,89$ & & \\
\hline 2 & & $903.706,11$ & $1.096 .704,00$ & & $192.997,89$ & & \\
\hline 3 & & $903.706,11$ & $1.096 .704,00$ & & $192.997,89$ & & \\
\hline 4 & & $903.706,11$ & $1.096 .704,00$ & & $192.997,89$ & & \\
\hline 5 & & $903.706,11$ & $1.096 .704,00$ & & $192.997,89$ & & \\
\hline 6 & & $903.706,11$ & $1.096 .704,00$ & & $192.997,89$ & & \\
\hline 7 & & $903.706,11$ & $1.096 .704,00$ & & $192.997,89$ & & \\
\hline 8 & & $903.706,11$ & $1.096 .704,00$ & & $192.997,89$ & & \\
\hline 9 & & $903.706,11$ & $1.096 .704,00$ & & $192.997,89$ & & \\
\hline 10 & & $903.706,11$ & $715.104,00$ & $1.419 .600,00$ & $1.230 .997,89$ & & \\
\hline
\end{tabular}

Fonte: Resultados originais da pesquisa

Para os bezerros, o índice de desmame foi baixo. No fim das inseminações, foram constatadas 735 matrizes prenhes. Destas, apenas 573 bezerros foram desmamados, o que representa perda de $22,04 \%$ por mortes nos períodos pré ou pós-natal. Houve muitos abortos em que não foi possível descobrir a causa $\mathrm{e}$ também muitas mortes de bezerros por falhas de colaboradores não qualificados, picadas de cobras e por descargas elétricas.

Com a venda dos 573 bezerros com peso médio de $208 \mathrm{~kg}$ e preço médio por $\mathrm{kg}$ de $\mathrm{R} \$ 6,00$, foi gerada uma receita anual de $\mathrm{R} \$ 715.104,00$. Como 26,5\% das matrizes apresentaram diagnóstico de gestação negativo, estas representaram receita na venda no valor de $\mathrm{R} \$$ 381.600,00 (265 matrizes gordas). Somando as receitas, obteve-se o valor anual de R\$1.096.704,00, exceto no último ano em que a receita foi de $\mathrm{R} \$ 1.419 .600,00$, motivada pelo valor residual deste fluxo de caixa (Tabela 5).

O tempo necessário para pagar o investimento inicial (Payback descontado) foi de 7,69 anos, enquanto que o Payback foi de 4,19 anos. Assim, o projeto será viável apenas após o período do Payback descontado.

Durante todo o processo de inseminação artificial em tempo fixo, observaram-se vários pontos positivos, quando comparados à realidade anterior da propriedade com base em criação de Nelore, como o melhoramento genético, a viabilidade econômica e ganho de peso dos bezerros provenientes de cruzamento industrial superior ao de bezerros Nelores. Porém, as principais vantagens da utilização da inseminação artificial em tempo fixo são a organização do trabalho na fazenda e do rebanho, 
identificação de matrizes inférteis e a certeza do cumprimento de um cronograma conforme projetado inicialmente.

\section{Conclusões}

Com a taxa mínima de atratividade de $15 \%$, é possível obter Valor Presente Líquido de R\$ 584.957,28, tornando o projeto viável em um intervalo de dez anos, pois o VPL foi maior que zero.

A Taxa Interna de Retorno é de 23,03\%, confirmando a viabilidade do projeto no período avaliado. O Payback é de 4,19 anos e o Payback descontado de 7,69 anos, tornando o projeto viável apenas após o período de 7,69 anos, por ser esse o tempo necessário para pagar o investimento inicial.

O valor residual obtido com a venda das matrizes ao final do período projetado e com a venda de descartes é necessário à viabilidade do projeto uma vez que apenas a venda dos bezerros não o tornaria viável.

A suplementação proteica para os bezerros, por auxiliar no ganho de peso em curto período de tempo, principalmente em anos com condições climáticas desfavoráveis à produção de forragem, pode ser um fator decisivo na viabilidade do projeto.

\section{Referências}

Artmann, T.A.; Toma, H.S.; Pinheiro, J.N.; Romero, J.; Carvalho, A. de M.; Monteiro T.C.D. 2014.

Melhoramento Genético de Bovinos $1 / 2$ Sangue

Taurino x $1 / 2$ Sangue Zebuino no Brasil. Revista

Científica eletrônica de Medicina Veterinária 22:1-20.
Baruselli, P. S; Ayres, H.; Souza, A. H.; Martins, C. M.; Gimenes, L. U.; Torres-Júnior, J. R. S. 2015.

Biotecnologia da reprodução em bovinos (2 simpósio internacional de reprodução animal aplicada), 113132.

Dantas, C.C.O.; Negrão, F. de M.; Geron, L.J. V.; Mexia, A. A. 2010. O uso da técnica do Creep-feeding na suplementação de bezerros. Publicações em Medicina Veterinária e Zootecnia 4:899-904.

Dias, L. L. R.; Orlandini, C. F.; Steiner, D.; Martins, W. D. C.; Boscarato, A. G.; Alberton, L. R. 2015.

Ganho de peso e características de carcaça de bovinos Nelore e meio sangue Angus-Nelore em regime de suplementação a pasto. Arquivos de ciências veterinárias e zoologia da UNIPAR 18:155160.

Furtado, D.A.; Tozzetti, D.S.; Avanza, M.F.B.; Dias, L.G.G.G. 2011. Inseminação artificial em tempo fixo em bovinos de corte. Revista científica eletrônica de medicina veterinária 16:1-25.

Inforzato, G.R.; Santos, W.R.M. dos; Climeni, B.S.O.; Dellalibera, F.L. 2008. Emprego de IATF (Inseminação Artificial em Tempo Fixo) como alternativa na reprodução da pecuária de corte. Revista científica eletrônica de medicina veterinária 11:1-8.

Pereira, A. M. V. S.; Muniz, C. A. S. D. 2013. Efeitos ambientais sobre características pré-desmama em bovinos da Raça Nelore Mocha. Seminário: Ciências Agrárias 1: 359-366. 